\title{
Presenças do índio: algumas reflexões a partir de um processo judicial
}

\author{
Maria Helena Cruz PISTORI* (FFLCH-USP)
}

RESUMO: Na análise de um processo judicial em que a vítima é um indígena, pretendemos levantar as estratégias das diferentes partes para configuração de sua identidade e o papel da opinião pública nessa construção. A análise se fundamentará primeiramente na sociossemiótica e, sobretudo, em Landowski.

PALAVRAS-CHAVE: presença; índio; processo judicial; sociossemiótica.

\begin{abstract}
This paper intends to analyze the presence of a native Indian victim in a juridical process. The process opponents and the public opinion present different configuration strategies in the construction of native Indian identity. We use sociosemiotics concepts, mainly Landowski's, to determine these strategies.
\end{abstract}

KEYWORDS: native Indian; presence; juridical process; socio-semiotics.

\footnotetext{
* Bolsista da CAPES, Université Paris 8, 2005.
} 
O Direito, por meio do discurso legislativo, produz enunciados performativos e normativos que instauram seres e coisas e instituem regras de comportamentos lícitos e ilícitos ( $c f$. Greimas e Landowski, 1976: 82-85); dessa forma, fornecem à sociedade um sistema de normas compartilhadas para a solução de conflitos, determinantes do que é considerado justo. Além disso, os resultados da persuasão e da eficiência discursiva, avaliados na sentença final, são produtos não apenas da argumentação das partes, mas também do fazer crer produzido pela opinião pública, particularmente se o caso vai a júri popular. Dessa maneira, o modo como se constrói a identidade da vítima no processo também produz efeitos de sentido importantes na persuasão.

Vamos tratar aqui de um processo judicial cuja vítima é um indígena. Trata-se do Processo n. ${ }^{\circ}$ 17.901/97, do Tribunal do Júri de Brasília, que analisa o homicídio de um índio pataxó, Galdino Jesus dos Santos, cometido por cinco jovens de classe média (ou média alta, talvez), um deles menor de 18 anos na ocasião, em Brasília, no dia 20 de abril de 1997, véspera do Dia do Índio.

Na realidade, embora a vítima seja um índio pataxó, o crime não foi cometido contra indígena como tal, conforme posição assumida pelo Ministério Público, responsável pela Denúncia e acusação dos réus, e posteriormente prevalente no Processo. Ao se posicionar contra a habilitação da FUNAI como assistente da acusação, em 13/06/2001, o Ministério Público esclarece:

Conforme decisão em todas as instâncias, o crime em tela não foi praticado contra índio, enquanto índio. Não se trata de disputa por direitos indígenas, nem de disputa por terrenos indígenas, e muito menos de crime contra a raça indígena. Não houve crime contra a etnia indígena, mas sim contra Galdino Jesus dos Santos, enquanto pessoa. Conforme já definitivamente registrado, os homicidas mataram-no pensando tratar-se de um mendigo. Sempre declararam nada ter contra índios. (fl.1751; itálicos nossos)

E, neste parágrafo, temos, em toda sua extensão, o problema da exclusão social: os homicidas mataram-no pensando tratar-se de um mendigo. Índio ou não, há o fato de que a vítima estava sozinha, abandonada, dormindo ao relento, parecia um mendigo... Este foi o motivo de sua escolha para a "brincadeira" que os acusados resolveram fazer, conforme depoimento nos autos.

No entanto, a mídia, pretensa porta-voz da opinião pública, utilizou bastante o fato de ser a vítima da etnia indígena e de estarem os índios, naquela ocasião, em Brasília, manifestando seus direitos, sobretudo os relativos às questões de terras. Não apenas a mídia se utilizou do fato, mas também os políticos, na medida em que se posicionar contra um fato bárbaro eventualmente pode render dividendos eleitorais. Os diferentes usos da opinião pública vão aparecer em várias das peças processuais.

Como podemos verificar, o tema do qual nos ocuparemos é inclusão/exclusão social, atual e historicamente definidas num processo judicial determinado. Procurar identificar como ocorre discursivamente (não trataremos aqui da questão actancial, relativa ao nível narrativo) a representação do indígena nas principais peças do processo será, então, nosso interesse central neste trabalho: como, por quem e por que é 
construída a identidade desta vítima. Basicamente, as posições se apresentam em torno de duas posições sociais contrárias e responsáveis, inclusive, pela grande repercussão do caso: a origem privilegiada dos criminosos, isto é, aqueles que estão em conjunção com os privilégios, a graça e o favor dos poderosos; e a origem desprivilegiada da vítima, em disjunção com os mesmos privilégios, graças e favores.

\section{Fundamentação teórica}

Ao tratarmos aqui da presença do índio neste processo, a idéia é buscar seu sentido dentro da própria dinâmica da prática social do Direito. Como nos lembra Greimas e Landowski, a cobertura discursiva do mundo é elaboração ideológica, embora se apresente como o próprio mundo social (1976: 84). Estamos pensando, primeiramente, na noção de presença expressa no Dicionário de semiótica (Greimas e Courtés, 1979: 290-291), uma noção que se confunde em parte com a própria existência semiótica. A presença nos aponta o sentido, mostra a tomada de posição do homem no mundo sensível. Na cadeia sintagmática constituída pelo processo judicial, ao lado do termo presente que refere a etnia, surgem outros como mendigo, pessoa, ser humano, depreendendo-se também deles o sentido por sua existência virtual (in absentia). Compreendida como da ordem do experimentado, anterior a toda organização modal, a construção de sentido, porém, é elaborada a partir de pelo menos dois sujeitos, pois a "construção do mundo é sempre um processo de interação com uma positividade exterior, uma alteridade" (Landowski, 2002; 2004: 26). Assim, a presença do índio ocorre diferentemente nos diferentes textos processuais e remete a modos de construção discursiva do referente relacionados a perspectivas definidas.

Mais especificamente em Presenças do outro (2002), Landowski busca, "a partir de um mínimo de traços e relações interdefinidos, um modelo - uma 'gramática' capaz de dar conta da maior diversidade possível de discursos e, sobretudo, de práticas identitárias" na sociedade (p.35). Propõe-nos, então, interessantes esquemas de construções identitárias tendo em vista grupos diferentes que convivem no mesmo tempo/espaço - tomados como realidades significantes -, cujas alteridades contribuem para a formação das próprias identidades; cujos estilos de vida expressam escolhas estratégicas de sobrevivência no grupo alheio; e cujos lugares ocupados definem uma presença para si, para o outro, para o mundo. Os rótulos que se atribuem mutuamente corresponderiam a uma maneira possível de construir o simulacro do outro. A normalidade é dada por um hipotético Sr. Todo Mundo, que ocuparia a posição central e seria o ponto de referência. Acreditamos que é uma forma de análise da presença que deve se revelar bastante produtiva neste processo. Apresentamos abaixo a organização esquemática das configurações identitárias problematizadas por Landowski, ressaltando que ele mesmo faz várias restrições à terminologia utilizada, afirmando, porém, que nenhum termo seria "inocente" (2002:15): 


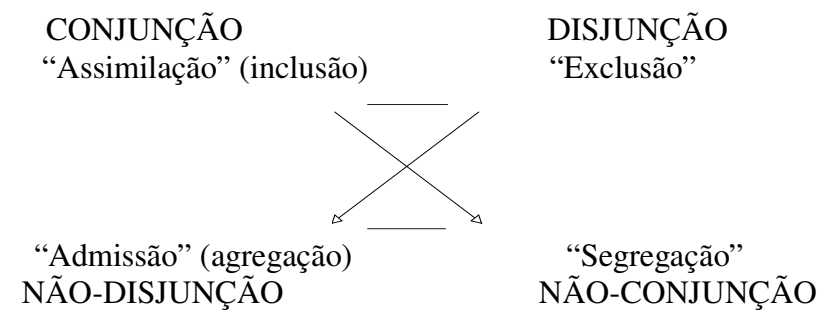

É importante lembrar, no entanto, que a proposta de Landowski (2002) procura dar conta de uma situação social bem diferente da nossa: é a situação identitária na nova Comunidade Européia, cujas fronteiras nacionais se diluíram e para onde têm afluído constantes levas de imigrantes de todos os cantos do mundo. Paradoxalmente, nosso índio, originalmente expulso das terras que lhe pertenciam, vai ser equiparado em nossa análise ao imigrante, pois é o Outro cuja presença causa estranhamento neste processo judicial. A diferença também ocorre, naturalmente, sob o prisma sócio-econômico. Em outras palavras, é nosso contexto político-social que ocasiona disparidades de toda ordem, construindo semioticamente a diferença.

A própria opinião sobre a etnia da vítima e sobre o crime vai se expressar em vários momentos; na realidade, a opinião pública, essa entidade abstrata, muitas vezes se manifesta no processo. Ela pertence ao domínio do plausível, do possível, do desejável, espaço passional do razoável e da racionalidade argumentativa; não enuncia uma verdade sobre o mundo, antes expressa um ponto de vista, resultado da reunião de elementos heterogêneos, associados segundo a lógica do verossímil (Mosca, 2002). Decisão de um sujeito, é na práxis enunciativa que ela se manifesta, falando preferentemente ora pelos homens da imprensa, ora pelos homens públicos. Tratando especificamente da mídia, Charaudeau afirma que definir opinião pública a partir dos veículos de comunicação não é fácil, pois não constituem uma atividade homogênea, mas o lugar em que se cruzam conhecimento e crenças de um lado e opiniões e apreciações de outro (2003:114). Ao mesmo tempo em que é objeto a ser conquistado, a opinião pública é também sujeito reflexivo a exercer sua ação sobre a própria sociedade.

Landowski (1992:19-43) trata de como a opinião pública fala por seus portavozes, particularmente os políticos, e de sua dupla vocação actancial: como destinador que fixa deveres, ou como adjuvante que dá poder aos Poderes estabelecidos. Mostra como, ao contrário do que se afirma correntemente a respeito da manipulação da opinião pública, ela pode ser a grande manipuladora. Instrumento de manipulações intersubjetivas, invocar a opinião é tentar modificar a conduta de algum outro sujeito, formulando os juízos possíveis do actante coletivo: fazer fazer, impedir de fazer, etc.; mas é também legitimar discursos.

Ainda sobre o termo opinião, verifica-se que designa ao mesmo tempo um actante do enunciado e posições enunciativas pertencentes ao nível discursivo que remetem à enunciação. A opinião pública tem ligação direta com os sujeitos da comunicação em busca de sua própria identidade: o sujeito enunciante que se qualifica como locutor autorizado a falar em nome da opinião ou tratar dela. São os políticos e a imprensa, com a ajuda de enquetes, pesquisas de opinião, que interpretam a opinião 
pública e fazem saber à sociedade o que ela quer. A opinião, enfim, não se presta à verificação experimental. Grande responsável por uma estratégia de persuasão social, por vezes aparece no discurso como se fosse o outro nome dado ao enunciatário.

\section{Assimilação e exclusão do indígena}

O processo, conforme já abordado no trecho introdutório do trabalho, trata do homicídio de um índio Pataxó. A Denúncia do Ministério Público ocorreu em 23 de abril de 1997 e o processo se encerra em 23 de maio de 2002, momento em que o Tribunal de Justiça do Distrito Federal nega provimento à apelação por redução de pena. Isto é, sua duração é praticamente de cinco anos, correspondendo a mais de duas mil páginas. Trataremos aqui apenas da presença do índio/vítima e de sua relação com a opinião pública. A seleção de excertos de peças processuais será feita visando à compreensão desses modos de presença da vítima, discursivamente construídos no processo, e do uso dessa presença persuasivamente.

Na DENÚNCIA oferecida pelo Ministério Público do Distrito Federal e Territórios em 23/04/1997, a vítima está nomeada e qualificada desde o início, na narração do delito:

... os denunciados, juntamente com o menor G., mataram GALDINO JESUS DOS SANTOS, índio pataxó...; procurando dar continuidade à diversão, ao passarem pelo banco da parada de ônibus onde dormia a vítima, supondo ser ela um mendigo, deliberaram sobre a idéia de dar continuidade à diversão, fazendo do pretenso mendigo uma tocha humana. (fl.03; itálicos nossos)

Vemos aí, na peça exordial do Processo, em primeiro lugar a especificação que destaca apenas um aspecto da vítima, o fato de ser um índio pataxó; isso já a mostra como diferente ao olhar de normalidade do "Sr. Todo Mundo" (no caso, o MP). Em seguida, temos a caracterização feita pelos réus em seu primeiro depoimento na Delegacia: supondo ser ela um mendigo, e não assumida pelo MP: pretenso mendigo. Assim, na própria Denúncia, já encontramos as duas formas básicas sob as quais a assimilação ou a exclusão do Outro aparecerá. O Ministério Público assume o discurso da assimilação, um discurso emitido por alguém "sem ódio nem preconceito"; na realidade, é um discurso pretensamente racional e argumentativo, que se revela um discurso do afeto puro e simples, visando à conjunção possível das identidades, a inclusão do Outro. Busca auxiliá-lo em suas necessidades; no caso, dando-lhe apoio jurídico, pois a promotoria fala não apenas em nome da sociedade, mas também do pai da vítima, senhor Juvenal Rodrigues dos Santos, habilitado como assistente de acusação, desde o início do processo (fls.211). Vejamos mais claramente este aspecto no trecho abaixo, constante da mesma peça processual:

Os denunciados utilizaram-se de recurso que impossibilitou a vítima de esboçar qualquer gesto defensivo, pois atacaram-no enquanto ela dormia. Galdino era índio e não podia imaginar que fosse atacado por homens brancos - tido como civilizados -, enquanto dormia, completamente desprotegido, sobre um banco de avenida principal da Capital Federal. (fl.04; grifado no original, itálicos nossos) 
Além da afetividade presente nos termos completamente desprotegido, temos também a estereotipia, mesmo que expressa com reservas, produzida socialmente para afirmar a diferença, tanto na identificação do branco (tido como civilizado) quanto na do índio (dormindo ao abrigo da natureza). Este discurso de assimilação do diferente, o indígena, vai se manter até o final do processo e tornar-se o discurso prevalente. Mais adiante veremos ainda outros trechos. A seu lado, temos o discurso da exclusão social apresentado pelos denunciados (mais adiante já réus), referindo-o como mendigo. É o discurso em que fazem a leitura do Outro, como o outro parece ser a seus olhos.

A defesa também procura assumir o discurso de assimilação no uso dos apreciativos axiológicos em relação ao crime e à vítima (lamentável episódio; desamparado), mas está bem próxima do discurso da exclusão, ao transferir a culpa do delito àqueles que tinham o dever constitucional de proteger os excluídos da sociedade:

O mendigo, na verdade, era um índio, desamparado daqueles que tinham o dever constitucional de dar-lhe proteção e abrigo. Dormia ao relento, na rua, onde todo mundo sabe não ser lugar de dormir.

O índio, tornado vítima, viera a Brasília comemorar o "Dia do Índio", 19 de abril, véspera do lamentável episódio. (fl.548)

A exclusão tende à negação do outro enquanto tal; no crime, a exclusão se manifesta de forma tão violenta que, mendigo ou índio, a vítima perde sua vida. E a metáfora (?) a ela referente utilizada pelo MP - tocha humana -, tem efeito emocional e persuasivo para suscitar a indignação do enunciatário. Interessante é notar que, nos depoimentos tomados a seguir e constantes dos autos (fls. 292-302), o termo mendigo desaparece. Nos interrogatórios dos acusados, temos: "a vítima estava deitada de lado... havia alguma coisa cobrindo suas pernas, parecida com 'um pano'... não estava trajando roupas típicas de um índio (destacamos ainda, aí, a estereotipia na construção do simulacro do Outro, expressão presente nos quatro depoimentos); “... uma pessoa dormindo na parada de ônibus...” “... deseja acrescentar que em momento algum passou pela sua cabeça ferir ou matar 'um ser humano igual a gente'”. A mídia havia divulgado a outra versão, aquela presente na Denúncia; logo, a referência à vítima como mendigo se modificou.

Há um outro texto nos autos em que o discurso da diferença como geradora da exclusão é assumido. Embora seja uma peça estranha ao processo judicial, está a ele juntada. É assinada por Maurício da Silva Gonçalves (membro da CAPOIB), Conselho de Articulação dos Povos e Organizações Indígenas do Brasil. Seminário "Galdino: Vigiar e Punir" (fls. 254-256) e tem por tema Terra e Exclusão dos Índios (06/05/1997). Na realidade, nela temos a apresentação da situação atual dos povos indígenas, com críticas à política neoliberal do governo, considerações sobre a impunidade em relação a crimes cometidos contra indígenas e reivindicação de punição no caso do

... cruel assassinato do nosso parente Galdino Jesus dos Santos. Crime como este, cometido contra um índio, caracteriza-se como uma atitude covarde e 
irresponsável contra a vida humana e a nação brasileira. O comportamento dos cinco criminosos que atearam fogo no nosso parente representa o resultado de uma mentalidade oriunda de elites racistas, excludentes, prepotentes e que se colocam acima da lei na certeza da sua impunidade (fl. 255; itálicos nossos).

Podemos perceber nela o reconhecimento do discurso da exclusão, assumido pelos denunciados no primeiro depoimento, como o próprio índio parece ser aos olhos de si mesmo. Essa exclusão é explicitamente apresentada e o momento da discussão sobre o crime é aproveitado para suscitar a grave reflexão sobre os seus [dos brasileiros] valores e o seu destino; para a expressão de reivindicações ao governo que nada faz em relação à dívida histórica da nação brasileira com os povos indígenas; e requerer punição exemplar para todos os criminosos que atentaram contra a vida e os direitos dos povos e lideranças indígenas, em especial, neste momento, para os assassinos de Galdino Jesus dos Santos. O índio se reconhece como excluído de suas terras e indica quem são os invasores: posseiros, fazendeiros, madeireiras, garimpeiros, mineradora ou o próprio governo brasileiro com os seus projetos desenvolvimentistas (hidrelétricas, estradas etc.). Verificamos aí, porém, nas reivindicações, a constatação de que a diferença deveria ser respeitada enquanto tal. Na realidade, há um querer ser diferente, um discurso de admissão da diferença, que tem por origem a si mesmo: o organismo signatário adota uma posição de justaposição da sociedade indígena em relação aos civilizados. Adapta-se porque não tem escolha, passa a agir como o grupo de referência, ao fazer reivindicações, mesmo que preserve eventuais "marcas de exotismo"; quer ter certeza de que sua própria maneira de ser não constitui obstáculo para que o Outro o compreenda (Landowski, 2002:50; 59).

Esse mesmo olhar de um Outro sobre o índio, admitindo-lhe a diferença, é encontrado no recurso assinado pelo Ministério Público Federal, solicitando que o crime seja julgado pela JUSTIÇA FEDERAL

... dada a especial qualidade da vítima, como tutelada por ente federal, vislumbrando a hipótese de que o crime seria da competência da JUSTIÇA FEDERAL, requisitamos... (...)

A fundação exercerá os poderes de representação ou assistência jurídica inerentes ao regime tutelar do índio. (fls.214, 216; grifado no original; itálicos nossos)

É uma peça que coloca em questão a tutela do índio pela Fundação Nacional do Índio, a FUNAI, conforme estabelecido pela Lei n. ${ }^{\circ}$ 6.001/73, o Estatuto do Índio. Verificamos que entre aquilo que é socialmente possível - não há possibilidade de assimilação real do Outro, a não ser que se percam identidades, e o aceitável - a exclusão é inaceitável do ponto de vista ético, há o discurso de admissão do diferente: aquele não está disjunto do enunciador, nem não-conjunto (segregado). A diferença agora é explicitamente problematizada na dimensão semiótica da produção da alteridade. O Estatuto do Índio e a existência da FUNAI são formas de resistência à uniformização cultural, ao mesmo tempo que proteção à minoria indígena, reconhecidamente espoliada de suas terras. 
No entanto, havendo o conflito de competência, o Superior Tribunal de Justiça julgou competente o Juízo de Direito da Vara do Tribunal do Júri. Assumiu, pois, o discurso da assimilação, o mesmo do Ministério Público do Distrito Federal e Territórios, prevalecente no processo. Transcrevemos abaixo outra peça processual do Ministério Público (de 13/06/2001). Aí, a vítima é vista não apenas como assimilada à sociedade "civilizada", mas como cidadã, sendo equiparada à personagem do caso que lhe serve de analogia:

Em resumo, se aculturado, o homicida é responsável criminalmente e, assim, entendido como cidadão sujeito às leis da República Federativa do Brasil, independentemente da Funai. Por todos os ângulos que se analise a questão, verifica-se a desnecessidade da assistência da Funai... (fl. 1754)

E, finalmente, de forma mais enfática, encontramos a admissão do índio como diferente no PARECER do Prof. Damásio E. de Jesus, de 13/10/1997, nomeado A solidariedade que mata ("um índio é tão bom quanto outro"). Dele vamos destacar apenas um trecho da longa epígrafe:

Pataxó - Hã-Hã-Hãe Galdino Jesus dos Santos morreu porque era indígena, porque era solidário. Estava em Brasília à procura do bem para sua tribo, tratando do andamento das ações judiciais relativas à posse e propriedade das terras onde morava. A solidariedade o matou. E as chamas que o consumiram não mataram só o homem. Atingiram a tribo Pataxó, porque 'um índio é tão bom quanto outro'. (fl.881; itálicos nossos)

\section{A opinião pública}

A opinião pública assume preponderantemente o discurso da assimilação, mas será utilizada pelas partes e pelos poderes decisórios de acordo com seus interesses. Para ilustrar seu papel no processo, também apresentaremos trechos de peças processuais diferentes: da defesa de um dos réus, do acórdão que negou provimento ao pedido de Hábeas Corpus ao mesmo réu, da sentença interlocutória que desclassificou o crime de homicídio para "lesões corporais seguidas de morte" e do Ministério Público.

As Alegações Finais do réu M., datada de 28/07/1997, apresentam as razões finais da defesa e o pedido de relaxamento de prisão preventiva. Sua epígrafe é bastante original, pois apresenta a foto de um acampamento de sem-terra (MST), sobre o qual paira uma faixa com os dizeres: PUNIÇÃO AOS ASSASSINOS DE GALDINO PATAXÓ E DE TODOS OS TRABALHADORES DO CAMPO. Grito da terra Brasil - 1997. CONTAG - CUT - CAPOIB - CNS - MONAP - MAB. Este vai ser o mote do texto: mostrar que a punição ao crime está sendo utilizada como bandeira das minorias, assim como dos políticos, todos manipulados pela mídia.

Referentemente ao abalo da opinião pública a que aludiu a douta Magistrada, se houve - é verdade - na primeira hora, tal ocorreu em razão, sobretudo, da posição social ocupada pelos familiares dos acusados e, sobretudo, pela infeliz coincidência de que o ato criminoso, sob todos os títulos deplorável, ocorreu 
no dia 20.4.97, contra um índio, cuja data comemorativa se dera no dia anterior, 19 de abril. E, ainda coincidentemente, no dia seguinte, 21.4.97, data do falecimento da vítima, festejava-se mais um aniversário de Brasília, capital federal. (...)

Daí o evidente alvoroço, aumentado com a marcha dos sem-terra, aqui chegada em 18.4.97, tudo contribuindo para o clima de consternação geral. (fl.541)

(...)

Estava aí formado o caldo de cultura para a imprensa plantar o quadro de uma verdadeira comoção social, em cuja base figuravam cinco "perigosos" adolescentes, sem quaisquer antecedentes criminais...

Os políticos logo pretenderam erigir o cadáver do pobre índio em bandeira política de suas ambições pessoais e eleitorais. (fl. 548)

É muito clara, nesses trechos (e em toda a peça), a oposição entre as referidas minorias e a posição social privilegiada dos acusados, apontada pela Defesa como a causa da comoção social expressa pela opinião pública. Muito mais haveria para se analisar nesses parágrafos; no entanto, aqui só queremos chamar a atenção para o papel da mídia, apresentada como manipuladora da opinião pública, e procurando modificar a conduta do julgador: a mídia engana a opinião pública baseada apenas no fato de que os acusados são privilegiados e a vítima, não. Se a Justiça a seguir, ela também estará enganando a opinião pública! O texto afirma ainda que a verdade, porém, é que nenhum dos acusados, até posterior apuração, sabia que a vítima era pessoa de origem indígena. Assumindo o discurso do anti-sujeito no processo (os réus), o texto pretende desvelar uma realidade "desconhecida" para o julgador; da mesma forma, a opinião pública e a mídia são apresentadas por ele como antidestinadores no processo.

Em 26/06/97, houve um pedido de relaxamento da prisão preventiva de um dos réus. Rejeitado o Habeas Corpus em acórdão do Tribunal de Justiça do Distrito Federal e Territórios, por dois votos contrários e um a favor, seguem abaixo trechos da ementa:

Habeas Corpus. Homicídio qualificado. Prisão preventiva fundamentada na garantia da ordem pública. Decisão suficientemente fundamentada. Ordem denegada.

Não se encontrando o decreto de custódia provisória fundamentado somente na gravidade do delito, o que, por si só, não o sustentaria, mas na notoriedade do fato e na sua repercussão negativa no seio da sociedade, justificado encontrase para a garantia da ordem pública. (fl.667; itálicos nossos)

Aí a opinião pública é invocada para justificar e legitimar a decisão: notoriedade do fato e sua repercussão negativa no seio da sociedade. É vista como um actante-destinador que fixa deveres, um "puro ser de razão que representa a nação" (Landowski, 1992: 31) de forma tão poderosa que é capaz de perturbar a ordem pública. É ela quem legitima a decisão, conforme ainda consta no voto vencido de um dos relatores: ... na verdade, o que houve foi medo da opinião pública, da mídia em geral e das autoridades do Governo em particular (fl. 669) - em posição que vê a opinião como não-destinador, que deveria, pois, ser afrontada. 
Já na Sentença de desclassificação do crime, a opinião pública é a adjuvante que dá poder ao Judiciário, legitimando a parte do discurso que nega a soltura dos acusados (que estão em prisão preventiva). Num trecho inicial, o texto assume o discurso da assimilação do diferente, naquele pretenso discurso racional $\mathrm{e}$ argumentativo da indignação, que o identifica ao discurso de todos: A conduta dos agentes, sem dúvida, deixou a todos indignados, tal a reprovabilidade da selvagem "brincadeira", independentemente de tratar-se de mendigo ou índio - ambos seres humanos (aspas no original). É o mesmo discurso da assimilação que vai justificar a segregação cautelar, já decretada anteriormente, como garantidora da ordem pública. A seguir, trecho da sentença que faz referência aos motivos expressos no acórdão que nega o Habeas Corpus, transcrito a seguir: ... persistem, ao menos parcialmente, os motivos que levaram à segregação cautelar. (fl.581).

No discurso "irresignado" com a decisão de desclassificação do crime do MP (26/08/97), no entanto, percebemos que essa sentença não decidiu inteiramente de acordo com a opinião pública: acatou-a como destinador-adjuvante apenas ao negar o HC, mas afrontou-a ao desclassificar o crime de homicídio. Dessa forma, a construção discursiva do texto da promotoria aponta para uma verdade maior, expressa na própria existência da lei definidora do que seja a justiça no caso, e revelada através da utilização do argumento a priori - partem-se de premissas diferentes para a aplicação da justiça a esse caso em comparação a todos os demais casos.

A questão não se resolve, d.m.v., na aferição do grau de coragem de "decidir" a causa "contra" a opinião pública. (...)

Alguns simpatizantes da causa defensiva proclamaram que a sentença demonstrou e significou "coragem de enfrentar toda a sociedade nacional e internacional para fazer justiça". Este raciocínio traz ínsita uma inverdade incontestável: a de que pronunciar os réus significaria injustiça. Chegou-se a dizer que, quem pensa diferentemente quer vingança ou linchamento. Por que para todos os presidiários do País a condenação significou "justiça" e para estes rapazes significaria "vingança", "linchamento"? (fl.638-639; itálicos, grifos e aspas no original)

É como se admitisse: há opiniões e opiniões, não são inteiramente confiáveis; existe um metadestinador mais próximo da razão - a lei, a que as opiniões devem se subordinar. E o Ministério Público coloca-se como o porta-voz dela.

\section{Algumas considerações finais}

Em relação à presença do índio neste processo, pudemos perceber que, conforme a gramática proposta por Landowski, predominou a oposição assimilação/exclusão. As diferenças são estanques e o emocional determina as relações. As referências à admissão da diferença como produtora de um estatuto jurídico diferenciado e, possivelmente, um julgamento diferenciado, neste caso não prevaleceram. Talvez isso envolva uma questão mais propriamente jurídica, cuja atinência extrapola os limites deste trabalho. Por outro lado, talvez sejam poucos, em nossa sociedade, os que consigam ver o diferente como sujeito distinto e autônomo. 
A relação entre a opinião pública e o fato de a vítima ser um indígena, no entanto, aparece explicitamente apenas no discurso da Defesa. É ele que alude ainda à comemoração do Dia do Índio na data anterior ao crime e também à marcha dos semterra, tanto ao longo do texto como na faixa que lhe serve de epígrafe. Isso acaba por acentuar sua visão excludente em relação à vítima.

$\mathrm{Na}$ realidade, a visão estanque do Outro, expressa na escolha do léxico da assimilação ou da exclusão, remete a valores de classe social, claramente perceptíveis neste processo. Remete a um contexto sócio-histórico de divisão social que não permite a emersão de sujeitos distintos e autônomos fora das classes sociais privilegiadas. E ainda há toda uma gradação nos posicionamentos, não abordada aqui. A presença do índio (ou mendigo) se encontra amalgamada com todas as dos demais excluídos de nossa sociedade de privilégios, ou, ao menos, dos minimamente privilegiados. Mais amplamente, porém, é a própria identidade social dos grupos minoritários que lhes parece ser negada.

Quanto à questão da opinião pública, entidade abstrata de estatuto emocional e não aferível experimentalmente, ela serve às estratégias de persuasão social e está à disposição de perspectivas várias, por vezes até opostas, conforme pudemos verificar neste processo. E acrescentamos: independentemente do fato de agir como manipuladora ou manipulada, num processo dessa natureza, parece que lhe é oferecida a catarse (oposta à persuasão) pela participação no espetáculo midiático que se torna um caso judicial com esses ingredientes: a nosso ver, uma purificação na mesma proporção daquela proporcionada pelas tragédias ao povo grego ( $c f$. Ricoeur, 1999: 488).

\section{REFERÊNCIAS BIBLIOGRÁFICAS}

Charaudeau, Patrick. El discurso de la información. La construcción del espejo social. Barcelona: Gedisa, 2003.

GREIMAS, A. J. e LANDOWSKI, E. Analyse sémiotique d'un discours juridique. In: Sémiotique et sciences sociales. Paris: Éditions du Seuil, 1991 (1976).

Greimas, A. J. e Courtes, J. Sémiotique. Dictionnaire raisonné de la théorie du langage. Paris: Hachette, 1979.

LANDOWSKI, E. A sociedade refletida. São Paulo: Educ/Pontes, 1992.

Presenças do outro. São Paulo: Perspectiva, 2002.

Pasions sans nom. Paris: PUF, 2004

MoscA, Lineide do Lago Salvador. "Subjetividade e formação de opinião na mídia impressa". In: GHILARDI, Maria Inês e BARzotTO, Valdir Heitor (org.). Nas telas da mídia. Campinas, SP: Alínea, 2002.

RICOEUR, Paul. Rhétorique, poétique, herméneutique. In Lectures 2. La contrée des philosophes. Paris: Seuil, 1999, pp.481-495.

\section{Como citar este artigo:}

PISTORI, Maria Helena Cruz. Presenças do índio: algumas reflexões a partir de um processo judicial. Estudos Semióticos, Número 3, São Paulo, 2007. Disponível em <www.fflch.usp.br/dl/semiotica/es>. Acesso em "dia/mês/ano". 